\title{
VII. Note on a curious effect of absorption of light
}

\section{Silvanus P. Thompson}

To cite this article: Silvanus P. Thompson (1877) VII. Note on a curious effect of absorption of light, Philosophical Magazine Series 5, 4:22, 61-62, DOI: 10.1080/14786447708639293

To link to this article: http://dx.doi.org/10.1080/14786447708639293

曲 Published online: 27 Jul 2009.

Submit your article to this journal 준

Џll Article views: 2

Q View related articles $\sqsubset$ 


\section{$\left[\begin{array}{ll}61 & ]\end{array}\right.$}

VII. Note on a Curious Effect of Absorption of Light. By Silvanus P. Thompson *.

WHEN experimenting upon the chromatic aherration of the eye, I had occasion, as mentioned in a recent communication to the Physical Society, to employ aqueous solutions of permanganate of potash of various degrees of density as absorbing media. It is well known that solutions of this salt, when sufficiently dense, absorb all the rays of the middle portion of the spectrum, while freely transmitting red, blue, and violet rays. Desiring, for the purposes of experiment, to obtain a medium which should transmit in equal intensity the two groups of rays of greatest and least refrangihility, I found it advisable to somewhat reduce the intensity of the red rays by passing the heam of light through a thin glass plate tinted with pale cobalt. This plate was placed in front of the glass trongh containing the permanganate solution. The compound medium was totally opaque to rays between lines $\mathrm{D}$ and $\mathrm{E}$, nearly opaque to rays between $\mathrm{C}$ and $\mathrm{D}$ in the orange and between $\mathrm{E}$ and $\mathrm{F}$ in the blue.

The surfaces of objects reflecting ordinary white light, when viewed through this medium, possessed a remarkable shimmer or lustre (almost like the "stereoscopic lustre" of Dove), as if there were two surfaces both reflecting light-a red surface, and a blue surface behind it and seen through the red surface.

When a coloured tablecloth or carpet was viewed through the medium, the portions coloured yellow, orange, or red appeared all equally red, and to be standing up above the surface in a plane nearer to the eye. The other portions (those of blue or green tint) appeared all alike of a blue-violet and as if sunk to a lower plane.

On observing a landscape-painting a similar effect was produced, the blues and greys of the picture appearing of a blueviolet, while all the yellows, reds, and even the bright greens of the picture stood out, in deep-red tints, almost detached from the plane of the picture.

On turning from coloured drawings to an actual spring landscape the rame startling phenomenon was repeated; for, while the sky gleamed with a steel-grey tint, the colour of the young green leaves, the sunlit grass, and the tiled hoise-roofs was aike blool-red. It was hard to resist the notion that the absorbent medium had actually changed the tint of the light ; but actual comparison with the spectroscope showed that the deep red observed existed among the rays of ordinary light reflected by the objects in question.

* Communicated by the Author. 
The only analogous effect that $I$ have observed in nature was about twelre months ago, when just after a sunset the slightly hazy but cloudless eastern sky in the Thames valley near Maidenhead was of a remarkable purple hue; and I noticed that trees and grass reflecting the light from this aspect presented a most unwonted reduess of tint.

VIII. On Action at a Distance in Dielectrics. By S. H. Burbury*.

TF K be the specific inductive eapacity of a dielectric me1 dium, $\mathrm{V}$ the potential of any electrified system, then, according to Professor Clerk-Maxwell (Electricity and Magnetism, vol.i.p. 86), the characteristic equations of $\mathrm{V}$ become, (1) at a point in the inedium where the volume-density of free electricity is $\rho$,

$$
\frac{d}{d x}\left(\mathrm{~K} \frac{d \mathrm{~V}}{d x}\right)+\frac{d}{d y}\left(\mathrm{~K} \frac{d \mathrm{~V}}{d y}\right)+\frac{d}{d z}\left(\mathrm{~K} \frac{d \mathrm{~V}}{d z}\right)+4 \pi \rho=0 ; .
$$

(2) at an electrified surface where the surface-density is $\sigma$,

$$
\mathrm{K}\left\{\frac{d V}{d \nu}-\frac{d V}{d \nu^{\prime}}\right\}+4 \pi \sigma=0 ; . . . .
$$

in which $\frac{d V}{d \nu}$ is the rate of increase of $V$ per unit of length of the normal on the outside of the surface measured outwards, and $\frac{d V}{d \nu^{\prime}}$ the increase in the same direction inside the surface. Assuming the truth of these equations, it can be shown that in a heterogeneous medium the attraction exerted by an electrified particle at $\mathrm{O}$ on another particle at $\mathrm{P}$ does not act generally in the line $\mathrm{OP}$, is not generally a function of the distance $\mathrm{OP}$, or of circumstances existing at $\mathrm{O}$ and $\mathrm{P}$ only, or at points in $\mathrm{OP}$ only. It becomes, then, a matter of irresistible inference that a particle at $O$ exerts no direct "action at a distance" on the particle at $\mathrm{P}$, but acts upon it derivatively through the medium.

For, let it be required to find the force of attraction at $P$ exerted by unit particle at $\mathrm{O}$. There being no other electrified body in the field except the particle, equation (A) becomes, at all points in space,

$$
\frac{d}{d x}\left(\mathrm{~K} \frac{d \mathrm{~V}}{d x}\right)+\frac{d}{d y}\left(\mathrm{~K} \frac{d \mathrm{~V}}{d y}\right)+\frac{d}{d z}\left(\mathrm{~K} \frac{d \mathrm{~V}}{d z}\right)=0 . \quad .
$$

If', now, $\mathrm{K}$ were constant, this would further reduce to

* Communicated by the Author. 